\title{
La utopía de los pobres y el reino de Dios
}

\section{Jon Sobrino \\ Centro de Reflexión Teológica, San Salvador.}

En mayo de este año el Centre d'Estudis Cristianisme i Justicia, Barcelona, cumplió veinte años de existencia. Coincidiendo con esa fecha, publicó un libro en agradecimiento y homenaje a José Ignacio González Faus, S. J., uno de sus fundadores y responsable del área teológica. El título del libro es De "Proyecto de hermano" a agradecimiento de hermanos, y en él colaboran conocidos teólogos, cercanos al Centre y amigos de José Ignacio. Los organizadores del libro pensaron que debía estar presente el tema de la utopia y me pidieron escribir un artículo sobre "La utopia de los pobres y el reino de Dios". Es el artículo que ofrezco a continuación, algo reelaborado. Pero antes de entrar en materia, quisiera retomar lo que lo ocasionó.

La Revista Latinoamericana de Teología y el Centro de Reflexión Teológica quieren unirse al agradecimiento-homenaje a José Ignacio. Si se me permite un recuerdo personal, en mayo de 1980, dos meses después del asesinato de Monseñor Romero, fui a recogerle al aeropuerto de San Salvador. Eran tiempos recios y conflictivos, y no era fácil conseguir profesores para nuestro Centro de Reflexión Teológica, que uniesen ciencia y fe, solidaridad y entereza ante los riesgos. José Ignacio vino a ayudarnos con toda naturalidad, y desde aquella primera vez, cuando impartió un curso sobre antropología teológica -lo que años después llegó a convertirse en uno de sus libros clásicos Proyecto de hermano-, hasta el dia de hoy ha estado muy cercano a nosotros, a la Iglesia y al pueblo salvadoreños. Con frecuencia ha venido a impartir cursos a la UCA y ha publicado numerosos artículos en esta revista, de temática variada y siempre de alta calidad.

Por todo esto, desde estas páginas, con toda sencillez y sinceridad, queremos decir a José Ignacio una palabra de gracias y desearle que siga producien- 
do teología, esa teología suya, sabia, aguda hasia con humor-, pero que sobre rodo humaniza a todos y da esperanza a los pequeños y oprimidos.

Me han pedido que escriba unas reflexiones sobre la relación entre "utopía", "pobres" y "reino de Dios". En este artículo me voy a concentrar en la relación entre utopía y pobres, aunque, como transfondo, esté presente el reino de Dios. La finalidad del artículo no es exegética, sino sistemática: replantear hoy la posibilidad y la necesidad de la utopía, y sus contornos fundamentales. La perspectiva ya ha quedado insinuada: desde los pobres, lo cual significa que, en un primer momento, no vamos a reflexionar en directo sobre la uropía-en-si, aunque analicemos después la ulopía universal y el aporte de los pobres a su constitución.

Esta tarea no es fácil, y ni siquiera sé si es posible, como he escrito en otro lugar: ipodemos los que ya damos la vida por supuesto pensar la realidad de quienes no la dan por supuesto, asumir su perspectiva, pensar sus sufrimientos y esperanzas, sus fracasos y utopías?'. Sin embargo, me parece muy necesario el intento de pensar su utopía, pues ésta no es -en lo fundamental-, sino el reverso de su clamor. Dado el pragmatismo reinante, la desilusión y desencanto de los mismos pobres, podrá discutirse la utilidad de pensar la utopía, pero lo que no puede discutirse - so pena de deshumanización total- es la obligación de escuchar el clamor de los pobres. Y quien bien lo escucha, barrunta al menos algo de su utopía.

Digamos desde el principio que el lugar de estas reflexiones es El Salvador, con décadas de pobreza e injusticia, represión y guerra, y el tercer mundo en general -en la actualidad especialmente el continente africano-, con la depredación, la imposición, el colonialismo, de los cuales es objeto, desde tiempo inmemorial; ahora, con la exclusión, las migraciones forzadas, el abismo creciente de la cruel desigualdad, el sida, más el olvido y el desprecio efectivos... En los momentos en que escribo estas líneas, campea el terrorismo, de a pie y de Estado, siendo este último el más estructural y duradero, y por ello, el más cruel e injusto. Y aunque sea sólo en una frase, digamos también desde el principio que, sobre todo para hablar hoy de utopía $-y$ no hacerla coincidir con sueños imposibles y pura veleidad-, tenemos presente la bondad, la gracia y lo que hemos Ilamado la santidad primordial, todo lo cual, en medio del drama, no ha muerto - del todo- y a veces emerge de forma impresionante.

1. J. Sobrino, La fe en Jesucristo. Ensayo desde las victimas, San Salvador, 2a.ed., 2001, pp.19-22. 
El artículo tiene tres partes. La primera es una reflexión formal sobre la utopía y cómo abordar una utopía que es específicamente de los pobres. La segunda es sobre el contenido de la utopía de los pobres. Y la tercera es sobre la utopía universal de la familia humana, en un mundo como el nuestro, y el aporte de los pobres a generarla - lo cual no es, por lo general, tenido en cuenta ${ }^{2}$.

\section{Planteamiento formal de la utopía desde los pobres}

\subsection{La utopía clásica y su cuestionamiento actual}

Desde antiguo, la humanidad ha sentido que el mundo real no es como lo desea el corazón humano. Por eso, en práclicamente todas las culturas, en leyendas y mitos, se ha expresado el anhelo - sueño, imaginación- de la aparición de un mundo ideal, que supere las limitaciones e imperfecciones de la existencia real y en el que ésta dé de sí, en plenitud. Desde una perspectiva lingüística, en la tradición occidental, esto se ha expresado con el término utopia, cuyo significado (lo más probable ambivalente), tomado en su conjunto, es muy apto para expresar ese anhelo. Utopía es eu-fopia, lo bueno y lo que es anhelado, y es ouropía, lo que no existe (o todavía-no existe), lo que no ha lugar, y por ello reduplicativamente anhelado. A esa utopía se corresponde de manera formal con esperanza -y según fes e ideologías - lambićn con praxis. Según eslo, el sentido de la aventura humana es que la utopía (lo que no ha lugar) se convierta en topía (lo que ha lugar) ${ }^{3}$.

En la tradición occidental, esto ya se formuló en La República de Platón, con su organización armónica de la sociedad, y cobró su sentido habitual en la Utopía de Tomás Moro. En la tradición bíblica, el equivalente a la utopía sería el proyecto inicial de Dios, en el Génesis, recalcando sobre todo su presupuesto teo-logal: el ser humano es imagen de Dios. Siéndolo en verdad, y sin desfigurar esa imagen, el mundo es bendición. Pero no ocurrió así, y la utopía se fue desplazando al futuro: en el lenguaje de la apocalíptica $-y$ después en el de Jesús-, la utopía es el reino de Dios. En nuestra generación, la monumental

2. Quisiera terminar esta inlroducción con una confesión. Dada la premura del tiempo, en este artículo uso material que aparecerá en otras publicaciones que tengo entre manos; especialmente, el libro Terremoto, terrorismo, barbarie y ufopía. El Salvador, Nueva York, Afganistán", Madrid, 2002, y el artículo "Redención de la globalización. Las víctimas", Concilium, 293 (2001) 801-811.

3. Esto es esencial a la misión de Jesús. "Jesús articula un dato radical de la existencia humana, su principio esperanza y su dimensión utópica. Y promete que ya no será utopía, objeto de ansiosa expectación, sino ropia (ver Lc 3,14), objeto de alegría para todo el pueblo (ver, Lc 2, 9)", L. Boff, "Salvación en Jesucristo y proceso de liberacón", Concilium 96 (1974) 378. 
obra de Ernsı Bloch Das Prinzip Hoffnung volvió a dar nuevo impulso al futuro, a la esperanza y a la utopia.

Hoy en día, sin embargo, el mundo de abundancia ignora o rechaza el pensamiento ulópico. A la ulopía se la declara imposible, porque no se han hecho reales las utopías pensadas por las democracias y los socialismos, lo cual es el reconocimiento de un desencanto metafísico, que si es tolerable y no ha llegado a convertirse ambientalmente en nihilismo, ello es debido al buen vivir malerial, que es posible para minorías. Se la declara ingenua, porque no se somete sin más al pragmatismo vigente. Se la declara peligrosa ${ }^{4}$, porque ofrece horizontes engañosos, ineficaces y que pueden llevar a trágicos resultados - las utopías religiosas, sobre todo, generadoras de fanatismo. Y tengo la convicción de que, de manera consciente $o$ inconsciente, también se la teme, sobre lodo por otra razón: traer a colación el tema de la utopía significa hurgar en dos problemas que no quieren ser enfrentados, porque supone hacer dos confesiones difíciles.

Mirando hacia adelante, en el tercer mundo, mundo de la pobreza, existe la utopía, la esperanza de que la realidad se lorne en bondad, y eso lleva a la pregunta de por qué no la hay en el mundo de abundancia. Ese mundo, teniendo tantas cosas, al parecer no tiene ya nada en realidad bueno que esperar como novedad, sino que sólo puede extrapolar. Mirando al pasado, ese mundo tiene que admitir que, si ha fallado la utopia, es que ha fallado el progreso, en cosas fundamentales. Baste recordar la famosa frase de Hanna Arendt: el siglo XX ha sido el siglo más cruel de la historia de la humanidad - y no parece que el siglo XXI ofrezca un aspecto muy halagüeño. Mantener la posibilidad de la utopía significaría, entonces, reconocer que hay que buscar otros caminos, distintos al del actual progreso. Y supondría reconocer que la hybris, la arrogancia, la negación de la transcendencia, no sólo no ha hecho posible la autoconstrucción sin límites del ser humano, sino que ha producido los graves males que conocemos.

Occidente, sin embargo, no acaba de pactar del todo con la pura faclualidad y desarrolla lo que podemos llamar — de forma análoga - "utopías adulteradas", ya realizadas o en camino de realizarse. Por mucho que pretendan ser científicos, mucho lenguaje y conceplualización de moda, recuerdan noslálgica, aunque de manera disciplinada para no caer en lo que no es políticamente correcto, la antigua utopía. Se habla así de "aldea planetaria", "globalización". Y se afima

4. Franz Hinkelammert critica las ilusiones transcendentales de la modernidad (Critica a la razón urópica, San Jose, 1984) por el peligro de tolalitarismo que encictran, y en ese sentido, descarta las utopias históricas. Pero mantiene la esperanza como esencial a lo humano y, con ello, un horizonte -utópico en la realidad- de una "sociedad en la que quepan lodos" (Cultura de la esperanza y sociedad sin exclusión", San José, 1995. 
que eso ya ha lugar, el "advenimiento, sin marcha atrás, del fin de la historia". Pero esas utopías son adulteradas. No son ou-topia, pues las declaran ya (irreversiblemente) existentes, y no son eu-topía, pues, en su conjunto, producen más males que bienes.

\subsection{La utopía de los pobres y el modo de abordarla}

Todo lo dicho sirve para encuadrar, por contraste, la rellexión sobre la utopía de los pobres. Comparando con lo anterior, el punlo de partida no es mero desasosiego del corazón humano, dada su limitación, sino el sufrimiento y clamor específicos del pobre, por el mero hecho de serlo. Hablamos, pues, desde el inicio de una ulopía que es pensada de manera parcial, debido a sus deslinatarios principales, lo cual es decisivo para determinar tanto su contenido como el método para pensarla —e intentar hacerla real. Digamos también, desde el principio, aunque lo analizaremos con mayor profundidad en el tercer punto, que, aunque parcial, la utopía de los pobres tiene un potencial universalizantc. Es decir, su ulopía -y no cualquier deseo, anhelo o veleidad-, es lo que hoy puede generar un dinamismo para que el mundo alcance un estado de cosas universal simplemente humano, mínimamente "aceplable". Y esta paradoja se expresa también en que lo "fundamental" de la ulopia, que en su núcleo no es otra cosa que la vida del pobre, no es lo esolérico y sublime, sino lo obvio y lo básico. Sin embargo, esta utopía de los pobres sigue siendo, en nuestro mundo, "la utopía mayor, pues: es lo bueno que no ha lugar para las mayorías del planeta, y, negada, es elemento esencial que imposibilita que la especie sea familia humana". La utopía de los pobres expresa la paradoja de toda utopía real hoy: es un mínimo-máximo. En palabras de Monseñor Romero, "es necesario defender lo mínimo que es el máximo don de Dios: la vida".

En dos cosas queremos insistir ahora. La primera es que consideramos al pobre como destinatario de la utopia $y$, por lo tanto, comprendemos el contenido de ésta a partir de aquél, y no a partir de la esencia-universal de lo humano. Pero, para ello, hay que comprender al "pobre" no sólo como lo limitado, como lo que todavia-no-ha-llegados a la plenitud de lo humano (cuyo ideal ya estaría realizado o incoado en el mundo de los no-pobres), sino como lo humano oprimido, deshumanizado de mil maneras. Esto significa que la comprensión y la realización de la utopía implica esencialmente "revertir" la realidad histórica, no

5. La conocida sentencia de Oscar Cullmann del "sí, pero todavía no" tiene sus ventajas para describir la dimensión escalológica del reino de Dios. Pero lomada de forma sistemática y en ámbitos distintos -como ocurre con frecuencia- tiene también sus peligros: ignora que hay realidades que no son el todavia-no de la afirmación, sino su negación, y a veces su contrario, cl ciertamente-no. En este sentido, cl pobre no es el que todavia-no es "rico y poderoso", sino cl que, ciertamentc, carece de forma acliva de bienes de vida. 
sólo extrapolar desde el presente, a través del progreso. E implica, de manera específica una praxis para superar la "perversión", no sólo la limitación, de la realidad actual.

La segunda es la implicación metodológica de lo dicho. Por ser los pobresempobrecidos sus destinalarios, la utopía ha de ser puesta en relación con la profecía, pues ella es la que pone en palabra la negatividad histórica de la realidad, no sólo la negatividad natural. De no ser así, si no se ponen juntas la visión utópica y la profética, pensar la utopía pudiera quedarse en fantasear el fuluro con mayor o menor plausibilidad y belleza literaria. Pero entonces "desaparece el impulso insoslayable del principio de realidad, sin el cual ambas (utopia y profecía) son juego mental, más que forma real"h. Para el proceso de humanización de la historia esto significa que la utopía funge como horizonte que atrae, pero el método -el camino real por el cual avanzar- es la denuncia de lo que existe, es decir, la profecía.

Según este método, podemos decir ya lo siguiente. Visto desde la profecía, los pobres son quienes no dan la vida y la dignidad por supuesto, los que no tienen palabra, ni nombre $-\mathrm{y}$ de tal manera que su realidad presente no es un todavía-no, sino un ciertamente-no. Desde aquí, sub specie contrarii, por superación de la profecía, se puede ofrecer una primera aproximación a la utopía: la utopía es mesa (vida) compartida (con dignidad), palabra (para expresarse con libertad) y nombre (para ser reconocido en el ámbito de la existencia). Esto no tiene por qué ser utopía para quienes —n la abundancia- dan por supuesta vida y dignidad, palabra y nombre. Pero sí lo es para los pobres.

$S u$ ulopía no será ya pensada como exlrapolación de lo que ya hay de mejor en el presente, sino como lo que rompe con la inercia de la historia e irrumpe como novedad. La ulopía no expresará "más —cuantitativamente- de lo mismo", ni siquiera "algo mejor de lo mismo". Es la novedad radical, es, en verdad, lo que afirma la Escritura: "un cielo nuevo y una tierra nueva" (Is 65, 17; $2 \mathrm{Pe} \mathrm{3,}$ 13; Ap 21, 1). Por ser de los pobres, la utopía es lo realmente nuevo.

La globalización (y otros sucedáneos de la utopía) ni siquiera intenta esa novedad radical. Lo que está en su centro sigue siendo la riqueza y el poder, con muchos conocimientos y medios de comunicación a su servicio. Con sólo eso, o fundamentalmente con eso, se pretende cambiar y salvar la sociedad, con lo cual, poco o nada cambia. Menos aún intenta "revertir" nada con seriedad. Y cuando promete —en la formulación de la nueva utopía - que "cabrán todos", no muestra convicción de que así será, pues nunca empieza con los pobres -y parece que éslos siempre llegan tarde para entrar al globo.

6. I. Ellacuria, "Ulopía y profetismo", Revista Latinoamericana de Teología 17 (1989) 141. 
Digamos, por último, que esta utopía de los pobres tiene que ser pensada en sus formas históricas, pues su contrario - la pobreza - tiene formas muy concretas. Tiene que generar una esperanza práxica, pues a nadie -y menos al pobre- - se le regala nada. Y tiene que contar con ser contracultura $\Gamma^{\prime}$, pues a lo largo de la historia, y ciertamente en la actualidad, priva y florece de modo impetérrito lo que Ellacuría llamó una "civilización de la riqueza", mientras que la utopía que proponemos es, en definitiva, una "civilización de la pobreza", es decir, exactamente su contrario.

\subsection{El lugar teológico para pensar la utopia de los pobres}

Todo lo que acabamos de decir puede ser cuestionado por la razón, en varias de sus formas: la razón pura y práctica, moderna, instrumental, posimoderna... Pensamos que tiene a su favor a la razón compasiva, la que es puesta en funcionamiento por la compasión anle pobres y víclimas.

Aunque ya casi se ha olvidado, antes se solia enfatizar la importancia del "lugar teológico" para el funcionamiento de la inteligencia teológica y la elaboración de sus contenidos. El lugar era lenido como decisivo para que la teología tomase uno u otro rumbo. Esto sigue siendo verdad, pero precisando que el lugar no son sólo auctoritates, textos (en la línea de Melchor Cano), ni sólo un ubi físico categorial (una universidad, una facultad, una comunidad). El lugar es un quid sustancial, es la realidad. Y la pregunta es dónde está esa "realidad real", desde la cual se pregunta $\longrightarrow$ al menos puede preguntarse - por la utopia, en general, y por la utopía de los pobres, en particular. La ideología de la globalización tiende a quitar aristas y relieve a los diversos lugares de la realidad, como si todo fuera expresión de lo mismo; pero no es así. Por lo que toca al tema de la utopía, así veía el problema Ignacio Ellacuría:

Se dice que en las culturas envejecidas ya no hay lugar para el profetismo y la utopía, sino para el pragmatismo y el egoísmo... en el mejor de los casos para la institucionalización, legalización y ritualización del espíritu que renueva todas las cosas. Sea o no inevilable esta situación, quedan, sin embargo, lugares donde la esperanza no es sin más la sumatoria de cálculos infinitesimales, sino el esperar y "esperanzar" contra todo juicio dogmático, que cierra el futuro del proyecto y de la lucha. Uno de esos lugares es América Latina".

7. Contraculrural no significa, cvidenlemente, hacer contra la llamada inculturación, lo cual supone, entre otras cosas, olorgar valor a culluras desvalorizadas, combalidas, ignoradas o arrasadas. Significa hacer en contra de la cultura dominante, la generada por la civilización de la riqueza. En este sentido, la inculturación en las culturas que están hoy abajo, en la historia, es ya en esencia contracultural.

B. Ibid., p. $141 s$. 
Que los pobres tengan utopía es cosa a constatar, y no se debe afirmar voluntaristamente. Pero, para descubrirla, es esencial —o muy importante- estar en el lugar teológico correcto. Y si en ellos se descubre la tal utopía, entonces, hay que tomarlo muy en serio, con apertura, agradecimiento y -aunque suene estridente- con obediencia. Metz habla, una y otra vez, de "la autoridad de los sufrientes", y hace años, escribimos sobre "la autoridad doctrinal de los pobres" "'. Pobres y sufrientes tienen algo que decir que es inapelable. Si ellos hablan de utopia, a ellos habrá que escuchar, si de utopía se trata. Más aún, ante ellos hay que practicar la obediencia, el ob-audire, el salir al encuentro de la palabra, de su palabra, para ver qué es utopía.

\section{La utopía de los pobres: vida y dignidad, nombre y palabra}

A continuación vamos a analizar algunos rasgos fundamentales de la pobreza, en la actualidad, cuya superación llevará a la comprensión de la utopía de los pobres. Este tipo de análisis tiene hoy gran importancia, pues ya han pasado los tiempos en que la pobreza era definida unilateralmente a partir de una sola realidad: la salisfacción de las necesidades básicas, el per cápita... Hoy se tienen en cuenta varios elementos. Así lo hacen el PNUD", el Banco Mundial'2, los teóricos ${ }^{13}$ del desarrollo... Nosotros vamos a presentar los que nos parecen ser los rasgos más clamorosos de la pobreza. Sin ignorar la realidad económica del pobre, damos mucha importancia a las realidades antropológicas.

9. "La compasión. Un programa universal del crislianismo en la época del pluralismo cultural y religioso", Revista Lationoameicana de Teología 55 (2002) 25-32.

10. En "La autoridad doctrinal del pucblo de Dios en Amćrica Latina", Concilium 200 (J985) 71-81.

11. El PNUD en su informe sobre Desarrollo humano 2000, pp.147-155, ofrece los siguicntes indicadores de pobreza: probabilidad al nacer de no sobrevivir hasta los cuarenta años de cdad, tasa de analfabctismo adulto, porcentaje de la población sin acecso a agua potable y al servicio de salud, porcentaje de niños menores de cinco años con peso insuficiente, lasa de descmpleo...

12. En una pequeña publicación del Banco Mundial, Informe sobre el desarrollo mundial 2000/2001. Lucha contra la pobreza, p. 3, se recogen testimonios de pobres sobre lo que ellos y ellas entienden por pobreza. Además de la falta de dinero, vivienda y trabajo, mencionan también sentimientos y estados de ánimo, que hacen la vida difícil y dura: inseguridad ante la enfermedad, humillación por causa de la dependencia, insulıs e indiferencia, cuando buscan ayuda, miedo a lodos: esposo, jefe de la aldea, policía...

13. Amarlya Sen, Development as freedom (Oxford, 1999) describe la pobreza como capability deprivation, pp. 87-110. 


\subsection{El sufrimiento: sin vida ni dignidad}

La pobreza es una realidad histórica y tiene por ello expresiones distintas a lo largo de la historia. Está delerminada por las posibilidades reales y su ausencia (en este caso, limilaciones y carencias) y por las relaciones que se establecen entre los seres humanos (en este caso, anonimato, desprecio). En la Palestina del liempo de Jesús, por ejemplo, los pobres podrían ser descritos de la siguiente manera:

los excluidos socialmente (leprosos y deficientes mentales), los marginados religiosamente (prostitutas y publicanos), los oprimidos culturalmente (mujeres y niños), los dependientes socialmente (viudas y huérfanos), los minusválidos fisicamente (sordos y mudos, lisiados y ciegos), los atormentados psicológicamente (posesos y epilépticos), los humildes espiritualmente (gente sencilla temerosa de Dios, pecadores arrepentidos) ${ }^{14}$.

Eslo se puede decir hoy de mil maneras ${ }^{15}$, añadiendo la feminización de la pobreza, la marginación de los enfermos de sida, la siluación de penuria e indignidad de indigenas, afroamericanos, emigranles indeseados, la realidad del Congo (casi dos millones de muertos, en tres años, en una guerra, cuyos hilos mueve Estados Unidos), Timor, Rwanda, los 1,300 millones que viven con menos de un dólar al día... ${ }^{\mathrm{k}}$. Hay, pues, carencias graves de todo lipo, a las cuales acompañan el miedo, la inseguridad, la desesperanza, el desencanto...

Y cuando estos lázaros son vistos junto a los epulones, a la pobreza se añade la indignidad, en forma de ofensa, insulto y desprecio. Hay muchas expresiones de ello, pero queremos insistir en el agravio comparativo entre seres humanos. En un campo español de fútbol, la adquisición de los veintidós jugadores que jugaron el 13 de febrero de 2002, por coincidencia el día del segundo terremoto de El Salvador, costó 125,000 millones de pesetas, más de 600 millones de dólares, dos o tres veces más que el presupuesto anual del Tchad. Es el agravio comparativo, insultante, impúdico.

Ahí están los pobres, a pesar de y en contra de la lógica de la globalización. Lo que tienen en común, a lo largo de la historia, es un ingente sufrimiento. Más allá de la limitación de la condición humana, el vivir es su máxima tarea, el mínimo de dignidad, su anhelo más hondo, el desprecio, su herida más profunda y la cercanía a la muerte - la muerte lenta de la pobreza y la muerte violenta en

14. A. Pieris, "Cristo más allá del dogma. Hacer cristología en el contexto de las religiones de los pobres (I)", Revista Latinoamericana de Teología 52 (2001) 14.

15. Cfr. G. Gutiérrez, "Situación y temas de la teología de la liberación", Revista Latinoamericana de Teología 50 (2000) 106-114.

16. En estos días hay que recordar a millones de afganos, quienes llevan décadas de cruel miseria. El presidente Bush les envió durante los bombardeos bocadillos. 
épocas de represión y guerra, pues los pobres son los que siempre ponen más muertos-, su amenaza más cercana.

Según el método profecía-utopía, el primer paso hacia la utopía es, pues, la superación de ese sufrimiento del pobre. La ulopía es, entonces, la vida y la dignidad. Tan es así, que según la fe cristiana, en ello está comprometido el mismo Dios y, a través de ello, se da a conocer. Monseñor Romero lo decía de manera intuitiva: "la gloria de Dios es que el pobre viva". Y Puebla lo reformuló con toda nitidez: Dios ama y defiende al pobre por el mero hecho de serlo (cfr. $\mathbf{N}$. 1142). Es la entraña del anuncio de Jesús, y por eso, a esa correlación incondicional Dios-pobres la hemos llamado el principio jesuánico, que -cristianamentefunge como criterio fundamental para la evaluación del bien y del mal, en nuestro caso, para la evaluación de la utopía.

\subsection{El anonimato: sin palabra ni nombre}

Es paradoja - y escándalo- que "la realidad más real" es "la realidad que menos se conoce", y por lo tanto, "la que menos existe". Lo que se da a conocer de ella no guarda en absoluto proporción con su masividad, con su crueldad, ni tampoco, como veremos, con su "santidad". Hay libertad de expresión, pero no hay voluntad de verdad, $y$ así hay mil modos de hacer que la pobreza no diga su palabra y hay mil modos de hacer enmudecer a las víctimas. Desde las más burdas (el asesinato del profeta), las más normales (negarles el acceso a los medios, porque no tienen dinero), las más falaces ("pronto llegará el día en que un mundo globalizado permita hablar a todos"), hasta las más sutiles ("si ha llegado el fin de la historia, no hay nada que hablar").

Y junto al silencio, la invisibilidad. En el régimen feudal había esclavos y en la revolución industrial, proletarios. Sus vidas eran crueles, pero visibles. Hoy se ha dado el paso a lo no-visible. Se habla - sin pestañear- de los excluidos, aquellos para quienes no hay lugar —máxima hipocresía de la globalización. Los pobres son, entonces, los "escamoteados". Y junto a la invisibilidad -lógicamente-, la insensibilidad generalizada, que lodavía no ha sido desterrada, a pesar de muchas instituciones y benemérilos movimientos de protesta. Esa insensibilidad amumba a los pobres a su lugar natural, que diría Aristóteles: la inexistencia. Los remile a un horizonte lejano, vago, sin rostro, entre irreal y exótico. Y no hay que extrañarse de ello, pues el pobre real, es decir, el "visible", es, por esencia, interpelante, juez sin apelación.

Cierto es que hay que tomar en serio lo que decía Rahner: "la realidad quiere tomar la palabra", y forcejea, así, para que los enmudecidos digan su palabra, y algunas veces con éxito. Las conocidas palabras de Monseñor Romero que vamos a recordar no son sólo de gran belleza oratoria, sino que quieren restablecer el equilibrio metafísico: "Estas homilías quieren ser la voz de los sin voz". Y en esa línea crecen también los movimientos antiglobalización $-\mathrm{y}$ se dejan oír. 
Pero, con todo, los pobres no tienen todavía "palabra". Son el in-fans, el que no puede hablar, el niño despreciado por ello. No pueden comunicar con eficacia su realidad. Al mundo de abundancia le suelen llegar algunas cifras -escalofriantesy algunas escenas de televisión -espeluznantes. Pero no le llega eficazmente la palabra de la mayoría de la humanidad.

Los pobres no lienen palabra, y tampoco tienen nombre. Esto ocurre en vida, pero también en muerle, incluso cuando ésa ha sido masiva, cruel, inocente e injusta, en guerras, genocidios y terrorismo, del de a pie y, sobre todo, del de Estado. (Dicho con respelo, la mayoría de las víctimas norteamericanas de Viet Nam tienen nombre, incluso grabado en monumentos; y algo parecido puede ocurrir con las víctimas de Nueva York y Washington.) Y los pobres tampoco tienen calendario. El IIS (11 de septiembre) es universalmente conocido. Nueva York tiene calendario. Pero el $7 O$ ( 7 de octubre), día en que comenzaron los bombardeos contra Afganistán, no lo es. Los países pobres no tienen calendario. El dejar en el anonimato, acto antidivino por antonomasia, pues Dios es "el que pone nombre", es una realidad masiva, recurrente y muy aclual. Es un escándalo, en cualquier mundo, y más si es democrático y cristiano. Lo hemos vivido en El Salvador y Centroamérica, y se vive en Los Grandes Lagos. En esos lugares, la inmensa mayoría de las víctimas ha quedado sin nombre, de hecho y (casi) de derecho: no lienen nombre, porque no son "ricos", sino "pobres". Son salvadoreños, hailianos, congoleños. Al mundo occidental no le interesan sus nombres. Son pobres.

$Y$ algo parecido - aunque esperamos que no de forma tan cruel, $y$ esperamos también que en esto vayan cambiando las cosas- puede suceder en las iglesias con los muertos en masacres - "mártires pasivos" los llamamos-, mayorías pobres e indefensas. Entre nosotros ha habido mártires notables, como Monseñor Romero o Ignacio Ellacuría, pero ha habido también miles de hombres y mujeres, niños y ancianos, inocentes, indefensos, víctimas de la persecución y la represión, asesinados de manera masiva y cruel en masacres, muchas veces por el simple hecho de tener material "subversivo" (homilías de Monseñor Romero, la Biblia), por vivir en zonas cercanas o controladas por la guerrilla, por ayudar humanitariamente (con comida, asistencia médica) a rebeldes y a veces también a soldados gubernamentales. En varios lugares se ha hecho un ingente esfuerzo para mantener sus nombres y honrarlos, y de ello pueden enorgullecerse las comunidades populares. Pero, en conjunto y de modo oficial, los cristianos no sabemos todavía qué hacer con ellos.

Las instancias eclesiales y teológicas no tienen nombre para esos seres humanos y cristianos, que han muerto una muerte, que es cruel históricamente, y que -cristianamente hablando, pensando en el siervo de Jahvé- es una muerte preclara, por duro y escandaloso que sea el decirlo. $\mathrm{Y}$ en lo que ahora quiero insistir es en que eso ocurre, aunque ya se han dado pasos importanles en una 
nueva comprensión del martirio. Así, más allá de la definición canónica, se dice hoy que mártir es no sólo quien muere "por causa de la fe", sino también "por causa de la justicia". (Rahner lo formuló de forma admirable, a propósito de Monseñor Romero".) En lo personal he intentado dar un paso más: mártir es quien, en lo sustancial, vive como Jesús, promueve la causa de Jesús, el reino de Dios, entra en conflicto y lucha contra el antirreino, y por todo ello, es dado a la muerte como Jesús. A esos mártires les hemos llamado mártires jesuánicos.

Pero con ser esto un avance importante, en mi opinión, se puede seguir ignorando lo más hiriente de la realidad y lo que menos se debe ignorar: las muertes masivas antes mencionadas. En este sentido, no deja de dar que pensar que la Iglesia haya considerado la posibilidad de que la muerte de soldados y combatientes pueda ser considerada como marlirio - buena es la reflexión ${ }^{16}$-. pero no ha sabido qué hacer con los masacrados inocentemente, a no ser con el recuerdo de los "santos niños inocenles", que ha quedado como trágico elemento teológico-decoralivo, en los relatos de la infancia de Jesús.

Pero ha ocurrido el milagro. En El Salvador, lo más fundamental que hicieron Mons. Romero, desde la pastoral, e I. Ellacuría, desde la teologia, fue hacer caer en la cuenta de esta situación -anómala o escandalosa, según se mire- y reparar el "pecado de deshonestidad e ingratilud". $Y$ pusieron nombres, "títulos de dignidad", como en la antigua cristología, a esas mayorías masacradas: son el "siervo sufriente" (Is 52,13-53,12), "el Cristo crucificado en la historia", el "pueblo crucificado". Más allá de problemas de lenguaje, más allá de la posibilidad de hacer uso inteligente de la analogía para que esas mayorías puedan ser comprendidas como mártires "canónicamente" o, al menos, "teológicamente", hay que recalcar lo decisivo: su fundamental semejanza con Cristo, en el momento culminante de su crucifixión.

Hemos puesto, pues, nombre a las víctimas. Las llamamos "mártires", "el Cristo crucificado en la historia". Pero pensamos - no sé si con audacia excesiva- que todavía hay que dar un paso más. Comparadas sus muertes con la de los mártires jesuánicos, incluso con la de Jesús, estas mayorías reflejan menos la praxis de defensa de los pobres y el carácler aclivo de lucha contra el antirreino, y también expresan menos la fidelidad, en medio de la persecución, y la libertad con que afrontar la muerte. Por otro lado, expresan más la inocencia histórica, pues nada han hecho (la acritud de la denuncia profética, por ejemplo) para "merecer" la muerte, más que ser pobres, y expresan más la indefensión, pues ni posibilidad física han tenido muchas veces para evitar la muerte, huyendo. $Y$

17. Véase su articulo, muchas veces cilado, "Dimensiones del martirio", Concilium 183 (1983) 323.

18. Santo Tomás reconoció esá posibilidad, In IV Senf, dist. $X L I X, q . V$, a. 3, quaest. 2 adII. Hoy en dia suele considerarse una quaestio disputata. 
sobre todo, expresan mejor que son esas mayorías las que cargan de forma injusta con un pecado que las ha ido destruyendo poco a poco en vida y las ha aniquilado por completo en muerle.

Esas mayorías, oprimidas en vida y masacradas en muerlc, son las que mejor expresan el ingente sufrimiento del mundo. Son los que, sin prelenderlo, sin desearlo y sin saberlo, "completan en su carne lo que falta a la pasión de Cristo". Son el analogatum princeps de los crucificados de este mundo - llámeseles mártires o no- a quienes Dios mira con infinila ternura. $Y$, sin embargo, sobre ellos se cierne un silencio muy inhumano y anticristiano, aunque coexista con la presentación de los grandes santos - "elitistamente", si se nos entiende bien-. contra lo cual los primeros en protestar de modo enérgico serían un Francisco de Asís y un Monseñor Romero.

¿Qué es entonces utopía? Si somos consecuentes con el principio profecíautopía, utopía es la negación de la muerte y del desprecio, del silencio y del anonimato. Utopía es, entonces, vida y dignidad, palabra y nombre. Indudablemente, utopía, también para los pobres, es "más" que eso. Pero "sin" eso no hay utopía. Monseñor Romero, no en cualquier realidad, sino en medio de la realidad salvadoreña, muy parecida a la de muchos otros lugares de pobres, lo dijo de modo admirable como ya lo hemos recordado: "Hay que Jefender lo mínimo, que es el máximo don de Dios: la vida".

Ya hemos recordado que instituciones como el PNUD o el Banco Mundial buscan definiciones más abarcadoras de lo que es pobreza que la mera carencia de bienes materiales, y de ahí que propongan —aunque de modo lácito- una ulopía para los pobres. Bienvenidas sean esas nuevas definiciones. Pero a nosotros nos parece decisivo añadir e insistir en que elemento esencial de la pobreza es la indignidad -el deshonor, dicen, era el mayor mal entre los israelitas-, el no tener - ni poder tener- palabra y el no tener nombre, estar condenados al anonimalo, porque el mundo de abundancia es miope hasla el exceso y no quiere ver más allá de sí mismo.

Terminemos con una advertencia obvia. No es nada fácil mantener la centralidad del pobre y su sufrimiento - y por lo tanto, su utopía - ciertamente, en la práctica, pero ni siquiera en la teoría. En las iglesias es cierto que siempre ha habido algún interés por el pobre, pero, concentrándonos en América Latina, con excepciones contadas, como en algunas iglesias post-Medellín, en la actualidad, no se hace de los pobres la realidad central eclesial, ni se arriesga la vida por la vida de ellos, como lo hizo su fundador. Su teologia, rara vez ha teorizado la parcialidad esencial de Dios hacia el pobre y la ultimidad de éste ante Dios. Además, a nivel de iglesia universal, relativamente pronto se impuso una comprensión global del cristianismo que lo dificultaba: de la mirada primordial de Dios al sufriente (pobre, víctima) se pasó a la mirada de Dios al pecador -aunque fuera para salvarlo por gracia. En las conocidas pala- 
bras de J. B. Melz se explican con lucidez las consecuencias de ese cambio epocal:

El cristianismo, de una religión sensible al sufrimienlo, se convirtió cada vez más en una religión sensible al pecado. Su mirada no se dirigió primero al sufrimiento de la crialura, sino a su culpa. Esto entumecía la sensibilidad por el sufrimiento ajeno y oscurecía la visión bíblica de la justicia de Dios que, después de Jesús, había de valer para toda hambre y sed ${ }^{19}$.

Este desvío del sufrimiento a la culpa se sigue notando hasta el día de hoy, de manera que los cristianos (sacerdotes y obispos incluidos) que se han centrado en primer lugar en el sufrimiento del pobre, aunque no ignoren la culpa, siempre han sido vistos como sospechosos. De igual manera, la pastoral "sacramental" siempre ha tenido, oficialmente, preeminencia sobre la pastoral de "aliviar el sufrimiento" y nada digamos de la pastoral de "erradicar la injusticia". Lo que ocurrió, en realidad, es que, aceptada la necesidad de institucionalización de la Iglesia, a medida que, después de la resurrección, se fue alejando ésta del movimiento jesuánico, fue adquiriendo cada vez más los rasgos de una religión de salvación y perdón del pecado.

Pero tampoco en la democracia - aun en el caso positivo de que se acepten sus valores y se ignoren sus limitaciones, hipocresías, incluso crímenes (sobre todo los que algunas democracias occidentales cometen en pueblos del tercer mundo fuera de sus propias fronteras)-, el pobre está en el centro de la realidad, de su interés, de sus utopias. Recordemos que, en su origen, hace dos siglos, los derechos humanos tenian en la mirada a los freemen ingleses, a los hombres blancos de Virgina, a los burgueses franceses, pero no a todos, ni siquiera a los que convivían con ellos: campesinos ingleses o franceses, negros y esclavos norteamericanos, aunque, en teoría, no se les negase el carácler de "seres humanos". En el centro estaba el ciudadano.

Las cosas han ido cambiando. En las democracias occidentales, los pobres han ido mejorando las condiciones de vida, aunque a veces también empeoran -recuérdese a los excluidos. Pero lo fundamental es que nunca aparecen como centro de las afanes de la sociedad, ni menos como su centro inspirador. De ahí que no hay que extrañarse de la crisis del "concepto" mismo de utopía, en las democracias actuales: no ponen al pobre en el centro, ni siquiera en el concepto. Esto impide que vida y dignidad puedan ser consideradas como utopía.

\section{El aporte de los pobres a la utopia universal: la familia humana}

Hasta ahora hemos hablado de la utopia de los pobres, y para determinarla, hemos seguido el método de profecía-utopía (leología dialéclica y negativa, si se

19. "Hacia una cristología después de Auschwitz", Selecciones de Teología 158 (2001) 114. Más recientemente, $c f r$. "La compasión". 
quiere). Nos hemos fijado, pues, en el pobre como carente. Ahora entramos en otro tema distinto y nos fijamos en el pobre como enriquecedor, por decirlo de alguna forma, y de tal manera que contribuye -con otros, pero manteniendo su aporte específico como esencial e insustituible - a la utopia de lodos: la construcción de la familia humana.

Qué debiera ser esa utopía universal hoy lo describió magistralmente I. Ellacuría, en el último artículo que publicó: "Ulopía y proletismo desde América Latina"z"l. Su tesis es que "la utopía cristiana, apuntada desde el profetismo de América Latina y, a su vez, orientada y regida por él, prenuncia de una manera hislórica la creación del hombre nuevo, de la tierra nueva y del cielo nuevo"2l, tesis que desarrolla con amplitud desde la realidad latinoamericana, y que otorga al pobre - civilización de la pobreza - un protagonismo principal.

Ese aporte de los pobres a la utopía universal es lo que queremos analizar a continuación, pero haciendo antes algunas aclaraciones previas, pues reconocer ese potencial al pobre es todo menos evidente. $Y$ repetimos que nos fijamos ante lodo en el potencial antropológico.

En primer lugar, es bueno recordar que algunos teologumena que versan sobre los pobres son hoy aceptados, con mayor o menor fortuna, al menos en teoría, por ejemplo, el de "la opción por los pobres", en el que el pobre es destinatario. Pero no ocurre lo mismo con otro teologumenon, relacionado con los pobres y que, en su formulación más radical, dice que "el pueblo crucificado Irae salvación", en el cual el pobre es agente. Eslo es lo que Ellacuría elevó a lesis fundamental hace 25 años, por pertenecer al meollo de la fe crisliana y por haber suficientes indicios históricos para quien quiera verlos ${ }^{22}$. Pero este teologumenon a mi entender no ha tenido éxito. Se lo recuerda cuando se hacen estudios históricos sobre Ellacuría, pero no se ha convertido en un clásico de la teología sistemática, lo cual, desde una perspectiva cristiana, la mulila y no hace justicia a la realidad de los pobres. Por eso, vamos a insistir machaconamente - por lo cual pedimos comprensión al leclor- en la dimensión acliva y salvífica del pobre. Para esclarecerlo, vemos el desacuerdo que muestra Molimann sobre este punto.

20. En Revista Latinoamericana de Teologia 17 (1989) 141-184.

21. Ibid., p. 164.

22. Tanto en su artículo de 1978 "El pueblo crucificado", como en el de 1989, "Utopia y profetismo desde América latina", Ellacuría puso como subtílulos, "Ensayo de soteriología histórica" y "Un ensayo concreto de soteriología histórica". El momento soteriológico de la realidad de los pobres es, pues, para él esencial. Véase también lo que escribimos en "Los pueblos crucificados, aclual siervo sufriente de Jahvé", Concilium 232 (1990) 506-508: "La salvación que traen los pueblos crucificados"; Jesucristo liberador, San Salvador, 4a.ed., 2001, pp. 425-440. 
Me parece que no es correcto hablar del "pueblo crucificado" que "quita el pecado del mundo" $y$, de ese modo, "redime" al mundo. Con ello no se hace más que glorificar y eternizar religiosamente el sufrimiento del pueblo. El pueblo no quiere salvar al mundo con su sufrimiento, sino ser finalmente redimido de su sufrimiento y llevar una vida humanamente digna ${ }^{23}$.

La última frase nos parece absolutamente correcla, pero no lalsifica necesariamente las anteriores. Es cierto que el pueblo crucificado no ofrece redención mecánica, por supuesto, ni menos de modo sacrificial. Pero también es cierto que el pueblo crucificado "carga con el pecado del mundo" (tesis histórica). Y en segundo lugar, aporta algo importante a la salvación del mundo, lo cual, en parte, es tesis de fe, de acuerdo a la teología del siervo, y en parte, es también lesis histórica, pues introduce en el mundo o al menos posibilita de manera histórica, como no lo hace ningún otra realidad, valores humanos y cristianos: luz, verdad, capacidad de conversión, perdón — sobre lo cual volveremos. Lo fundamental, sin embargo, para cl pueblo crucificado, es que al "salvar" al mundo, lo capacita para que éste, a su vez, se vuelque sobre la salvación y liberación del pueblo crucificado. En cualquier caso, no se pretende glorificar y eternizar el suf́rimiento del pueblo, sino erradicarlo, "bajar a los pueblos crucificados de la cruz", como se ha dicho tantas veces ${ }^{24}$.

En cualquier caso, lo que ahora nos interesa recalcar es que la realidad del pueblo crucificado, de las víctimas, de los pobres, no se reduce a sufrimiento y carencia, sino que poseen un potencial para aportar, no sólo para recibir; en nuestro caso, para aportar a la constitución de la utopía —universal- de la familia humana. Y esto nos lleva a la segunda aclaración.

Lo que hemos afirmado no es ingenuidad, ni volunlarismo, que ignora la realidad negativa de los pobres. La cruda realidad es que en ese mundo está también muy presente la maldad humana, los niños-soldados, formas arcaicas de crueldad hacia la mujer, fanatismos culturales y religiosos, dirigentes crueles, criminales a veces, corruplos... El mysterium iniquitaris está, pues, muy presente en el mundo de los pobres. Por eso, preguntarse qué puede dar ese mundo y afirmarlo como necesario y benéfico, pareciera ser cosa de ingenuos, ilusos, obnubilados con el mito del "buen salvaje", de lo que a veces se acusa a quienes defienden así la utopía.

23. “Teologia Latinoamericana", en Luiz Carlos Susin (ed.), El mar se abrió, Santander, 2001 , p. 209.

24. I. Ellacuria, "Las iglesıas latinoamericanas interpelan a la Iglesia de España", Sal Terrae 3 (1982) 230. Así lo muestran, además, su vida y su muerte. Trabajó por bajar de la cruz al pueblo crucificado, pero eso no quita que recibiera de él y que -como realidad y, o como ocasión- enconirara en él luz, verdad, gracia, fuerza para la conversión, lodo lo cual bien puede ser expresión de salvación histórica. 
Pero las cosas no son tan simples, ni menos pueden llevar a que el mundo de abundancia se desentienda de su responsabilidad hacia el mundo de los pobres. Por una parte, esos males, aun los monstruosos, tienen claramente su contrapartida en el mundo de la abundancia — por lo general en formas más frías, sofisticadas, elegantes incluso, pero no menos crueles - y a lo largo de la historia, en forma más masiva y cruel. A veces son respuesta a otros males, que les han sido impuestos. Y no hay que olvidar que el opresor queda introyectado en el oprimido, como decía Paulo Freire. Nada, pues, de ingenuidad. Pero, por otra parte, sigue siendo verdad que a pesar de sus limitaciones, males y pecados, en el mundo de los pobres existen valores humanizantes, la santidad primordial, la solidaridad entre los mismos pobres, los cuales pueden humanizar a todos. Veámoslo, aclarando desde el principio que en el análisis a veces se entrelazan tesis de fe y tesis históricas.

\subsection{Los pobres proponen la dirección hacia la utopía universa]}

Hace años se hablaba de los pobres como sujelos y agentes de liberación, pero no es ese el tema que ahora nos inleresa, ni el significado que damos al aporte de los pobres. Lo que queremos decir es que, organizados o no, los pobres apuntan en la dirección fundamental hacia la utopia, lo cual aparece más claro si se compara el dinamismo que, histórica, no sólo teológicamente, genera el mundo de la pobreza con el dinamismo que genera el mundo de la riqueza. Muy bien lo vio -en un contexto personal, aunque traducible a lo social- Ignacio de Loyola. Por ello, recordemos lo fundamental de su intuición (tesis que es una mezcla de fe y de historia).

El lector familiarizado con los Ejercicios espirituales recordará que, reflexionando sobre el modo de elegir lo verdaderamente humano, san Ignacio ofrece dos caminos: uno que lleva a la soberbia, y de ahi a todos los males, y otro que lleva a la humildad, y de ahí a lodos los bienes. No es difícil historizar $^{2 s}$ —en teoría- esta intuición para la realidad social. Lo importante es que todo comienza o con la riqueza o con la pobreza, y que cada una de estas realidades tiene un dinamismo propio. En su lenguaje, la riqueza, por sus pasos, lleva a los vanos honores, de ahí a la soberbia y de ahí a lodos los vicios. En nuestro lenguaje, el "principio riqueza" lleva al desprecio del otro, de ahí a la prepolencia, y de ahí a la deshumanización. La pobreza, por el contrario, lleva, por sus pasos, a sufrir afrentas por la verdad y la justicia, de ahí a la humildad y de ahí a todas las virtudes. En nuestro lenguaje, el "principio pobreza" lleva a la sencillez, a la austeridad, de ahí a la solidaridad y de ahí a formar parte de la familia humana, la humanización.

25. Cfr. J. Ellacuría, "Lectura latinoamericana de los Ejercicios espirituales de san Ignacio", Revisła Latinoamericana de Treología 23 (1991) 111.147. 
Este proceso es dialéctico, pobreza y riqueza se oponen. Pero, además, es duélico: hay que elegir la pobreza en contra de la riqueza, y así en todo lo demás. Según esto, aunque quede claro el primer paso hacia la utopía, caminar hacia ella es todo menos ingenuo. Y no sólo porque la utopía es lo-que-no-es, sino porque siempre habrá poderosas fuerzas que se le oponen -aunque la ulopía sea algo sencillo y benéfico, de modo que todos debieran estar a su favor: vida y dignidad, palabra y nombre. Ojalá esto deje de ser algún día - prontoou-topia, lo que no ha lugar, y llegue a ser topia, para lo que sí hay lugar en el mundo. Pero, mientras tanto, dos cosas nos enseña lo que hemos expuesto: que no hay que olvidar que el pecado del mundo se opone a la vida del pobre y que no hay que ser ingenuos, cuando se trata de propiciar la utopía como vida de los pobres. En lenguaje de los evangelios, sea lo que fuere la utopía del reino de Dios, contra ella se alza siempre el antirreino. Sea lo que fuere hoy la utopía, si en ella van a estar los pobres, encontrará resistencia a muerte.

En cualquier caso, que es lo que ahora nos interesa recalcar, el mundo de los pobres pone a la humanidad en la dirección correcta hacia la ulopía.

\subsection{Civilización de la pobreza}

El mundo de la pobreza no sólo lleva a la humanización, ni su relación con la riqueza es sólo el de enfrentamiento dialéctico y duélico, sino que -contra todas las apariencias y contra toda la ideología dominante- es el mundo que salva al mundo de la riqueza y, por ello, tiene un polencial para generar una utopía universal. Esto es verdad central, en la fe cristiana (tesis de fe), pero - aunque se repita de manera ortodoxa - no suele ser historizado por iglesias y teologías (con lo cual sería también una tesis histórica), sino olímpicamente ignorado. Y la razón, de nuevo, es el lugar teológico.

Deciamos antes que para poner en conjunción utopía y profecía se necesita un lugar preciso: el tercer mundo. Lo mismo ocurre ahora: descubrir el polencial salvífico de los pobres, su capacidad de construir utopía, no ocurre en cualquier lugar, pero sí en el tercer mundo. En Asia dicen: "los pobres son convocados a ser mediadores de la salvación de los ricos y los débiles son llamados a liberar a los fuertes"2n. En Africa, en un contexto intereclesial, dicen: "La Iglesia de Africa... a través de su pobreza y su humildad debe recordar a todas sus iglesias hermanas lo esencial de las bienaventuranzas y anunciar la buena nueva de la liberación a las que han sucumbido a la tentación del poder, las riquezas y la dominación"27.

26. A. Pieris, "Cristo más allá del dogma. Hacer cristología en el conlexto de las religiones de los pobres" (I), Reviala Latinoamericana de Teología 52 (2001)16.

27. M. Veng, "Iglesia y solidaridad con los pobres de Africa: empobrecimiento antropológico", en Identidad africana y cristiana, Estella, 1999, p. 273s. Veng fue el primer jesuila camerunés. Murió asesinado en 1995. 
Esa "salvación de los ricos" —llevada a cabo por los pobres y que revierte en la suya propia- es un estado de cosas que Ellacuría llamó "civilización de lo pobreza". En ella

la pobreza ya no sería la privación de lo necesario y fundamental debida a la acción histórica de grupos o clases sociales y de naciones o conjunto de naciones, sino un estado universal de cosas en que está garantizada la satisfacción de las necesidades fundamentales, la libertad de las opciones personales y un ámbito de crealividad personal y comunitaria que permita la aparición de nuevas formas de vida y cultura, nuevas relaciones con la naturaleza, con los demás hombres, consigo mismo y con Dios ${ }^{2 s}$.

Esta descripción es abstracta y utópica, pero no es inconsulta, pues la civilización de la pobreza responde a las posibilidades reales del mundo actual; no así la civilización de la riqueza. Y además, no es reduccionista —en el sentido de garantizar la vida "en bruto"-, sino que hace central en la utopía el espíritu de lo humano, tan ausente, o sólo pálidamente presente, en concepciones acluales del progreso. Ellacuría aboga por

un espíritu que no se verá ahogado por el ansia de tener más que el otro, por el ansia concupiscente de tener loda suerte de superfluidades, cuando a la mayor parte de la humanidad le falta lo necesario. Podrá entonces florecer el espíritu, la inmensa riqueza espiritual y humana de los pobres y los pueblos del tercer mundo, hoy ahogada por la miseria y por la imposición de modelos culturales más desanollados en algunos aspectos, pero no por eso más plenamente humanos ${ }^{29}$.

Hace siglos, Isaías formuló la utopía con otras palabras: "Edificarán casas y las habitarán, plantarán viñas y comerán su fruto. No edificarán para que otro habite, no plantarán para que otro coma" (Is 65, 21s). Para conslruir casas y para que la tierra dé frutos para los pobres de hoy, miles de millones, se necesitan conocimientos y tecnologías de todo tipo. Pero esos conocimientos por sí mismos no bastan, como lo muestra cruelmente nuestra realidad. Son "necesarios", pero no son "suficientes". Se necesita el "sueño" de los pobres para que las "casas" que se edifican sean oikos, hogar, expresión de la vida primaria, y para que "la tierra" que se trabaja exprese la maternalidad de la creación de Dios, y por ello, automáticamente, la hermandad universal. Así se irá convitiendo el mundo en hogar, en familia humana. $Y$ los pobres saben de esto más que los que no lo son.

\section{Realidades humanizantes}

Por lo que son, cercanos a la vida, por una parte, los pobres ofrecen elementos para consiruir la utopía. O dicho de otra forma, sin ellos, el llamado progreso

28. "El reino de Dios y el paro en el lercer mundo", Concilium 180 (1982) 595.

29. "Misión actual de la Compañía de Jesús", p. 119s. 
no se dirige hacia la ulopía, sino hacia el egoísmo, el lujo, la prepotencia. Eslos elementos no son la utopía (como los milagros y las curaciones de Jesús no eran el reino), pero expresan dimensiones importantes de la familia humana o de su posibilidad. En cualquier caso, mantienen la esperanza de que algún día la utopía scrá realidad. Y — no lo olvidemos- eslos signos — del reino o de la utopía- ayudan a desenmascarar muchos de los falsos signos de progreso, que ofrece el mundo aclual. Mencionemos algunos de ellos.

Sin "conversión" no hay utopía. Con-versión del corazón y re-versión de la historia son absolutamente necesarias para cambiar la historia, en dirección de la utopía, y los pobres pueden mover a ello. No asi los ricos a quienes, estructuralmente hablando, no les interesa cambiar, pues les va bien. Estos hacen todo lo posible para mantener las cosas como están, aunque ello lleve a la muerte, la destrucción, el terrorismo y la guerra, si es necesario. Y tampoco parece ocurrírseles que sean "ellos" los que tienen que cambiar, sino los "otros", los pobres - sobre todo cuando éslos han decidido dejar de serlo, organizarse y luchan por vivir.

Además, cuando los poderosos se deciden a cambiar la situación, o se sienten forzados a ello para evitar desastres que les afecten, confían ante todo en el poder - no en la fuerza del bien-, lo que se les ha hecho como una especie de segunda naturaleza. Confían en una todopoderosa globalización, movida por el poder económico, no en la solidaridad, en el perdón, ofrecido y aceptado, en los signos de reconciliación... (El terrorismo y la guerra de estos días muestran que no se desea usar ningún medio "Jébil", que exprese de algún modo respeto, reconocimiento de las propias responsabilidades; y nada digamos de mostrar afecto al otro.)

Sin "verdad" no hay utopía, y los pobres, sub specie contrarii, muestran mejor que ninguna otra cosa esa verdad. Qué sea nuestro mundo no lo dicen a cabalidad ni Naciones Unidas, ni el Banco Mundial, ni el Fondo Monelario Internacional, sino los 2,000 millones para quienes no hay vivienda mínima, en este milenio que comienza. Y no sólo la muestran, sino que la desenmascaran, en conlra de fuerzas muy poderosas del maquillaje mediático: los más de 100,000 muertos en Irak desenmascararon lo que ocultaban bombardeos perfectos y piadosos, pues, televisivamente, sólo destruían con precisión puentes, no personas.

En estas ocasiones, siempre vienen a la memoria las ironías" de Ellacuría, que descubren mucha verdad: la verdad del primer mundo se ve cuando éste se

30. No me resisto a contar la siguiente anécdota, irónica y portadora de verdad, del recién fallecido congresista por Massachusselts, Joc Moakley, defensor de los cmigrantes salvadoreños, acusador incansable del cjército salvadoreño por su participación en los asesinatos de la UCA y defensor de muchas otras causas nobles. Solía 
mira en el tercer mundo como en un espejo invertido $y$, al verse desfigurado, ve su verdadera figura; su verdadera salud se descubre - según la técnica médica del coproanálisis- en las heces que produce: pobreza y muerte, en el tercer mundo. Los pobres son los que desenmascaran la carne lacerada del mundo, con lo cual le dan la razón a Juan: "el maligno es asesino (lacerante) y mentiroso (encubridor)", y en ese orden. Los pobres, además, no le lemen a la verdad. Saben que está en su favor y que, muchas veces, es lo único que tienen a su favor. Se encubre a los pobres, pero una vez salidos de su anonimato, muestran la verdad, que indica el camino correcto a la utopía.

Sin "sueño"." no hay utopia. Cuál sea ese sueño de los pobres —además de lo obvio: alimentación, salud, educación....- es cosa de preguntarles a ellos. Hace años, en plena guerra, en un relugio a donde huyó para salvar la vida, decía la señora Santos, una campesina de 80 años:

Primero Dios que cuando haiga liberación ya no tendrá que pasar nadie otra cosa más. Ya quedará todo sano, siempre trabajando, pero sin que a uno le traten mal porque no es señor y no sabe leer... Entonces, eso pienso yo. Volveremos a doblar la milpa y nos dará gusto. $Y$ tendremos los primeros elolillos del lugar, allí no más, en la casa donde antes scmbrábamos. Y en la milpa, todos contentos. Recogeremos, pues, los elotes, ¿verdad que sí? Primero Dios'?.

¿No es esto un trasunto de una civilización de la pobreza, de la familia humana, de la ulopía?

Sin "santidad" no hay utopia. Lo verdaderamente humano -y también la utopía- siempre necesita santidad, y en esto nos vamos a detener un poco más. Pues bien, los pobres la aportan, a veces por la bondad y heroicidad, y también por lo que hemos llamado la santidad primordial. Entre nosolros, Monseñor Romero atribuía al pueblo una capacidad inagotable de encontrar salidas a las dificultades más graves, lo cual a veces decía en palabras escalofriantes muy suyas. "El día en que las fuerzas del mal nos dejaran sin esta maravilla [la radio] de que ellos disponen en abundancia... sepan que nada malo nos han hecho. Al contrario, seremos entonces más 'vivientes micrófonos' del Señor y pronuncia-

decir que cuando queria enterarse, de verdad, de la situación de los países del tercer mundo para volar en asuntos de política exterior, no acudia al Departamento de Estado, sino que se ponía en contacto con las religiosas que trabajaban con los pobres, en esos paises.

31. El sueño ha sido siempre una metáfora para apuntar a la utopía, también hoy. I have a dream, decia Martin Luther King. En ambientes eclesiales, no pudiendo hablar con libertad, el cardenal Hume y, después, el cardenal Martini usaron el lenguaje del suē̃o: una iglesia colegial, fraterna...

32. "Meditación ante el pueblo crucificado", Sal Terrae (1986) 98. 
remos por todas partes sus palabras" (27 de enero, de 1980)... El día en que mataran a los sacerdotes y quedaran ustedes, "cada uno tiene que ser un micrófono de Dios, un mensajero un profeta" (8 de julio, de 1979). También Ellacuría recalcaba "la inmensa riqueza espiritual y humana que poseen los pobres y los pueblos del tercer mundo"3.".

Así hablaban nuestros teóricos de la utopía: en los pobres hay un gran potencial para construir vida y humanización. Puebla — lan olvidada como ellostambién lo recalcó, en base a mucha experiencia acumulada. En los pobres muchas veces se hacen presentes virludes insignes: "solidaridad, servicio, sencillez, disponibilidad a acoger el don de Dios" (No. 1147), valores, digamos, de todos los tiempos; y también la fortaleza en el sufrimiento, en el compromiso hasta el martirio, perdón al ofensor, valores novedosos en tiempos de persecución, compromiso y liberación, más específicamente jesuánicos. La conclusión, en lenguaje eclesial, no puede ser más elocuente: los pobres poseen "un potencial evangelizador" (ibid.).

¿Es esto verdad? ¿Es idealización, como se objeta tantas veces? La constatación histórica, en su pura factualidad, según tiempos y lugares, es ambigua, por supuesto. En los pobres, como en todo el mundo, hay gracia y pecado. Pero creo que esto ocurre con dos diferencias con respecto a otros grupos humanos. Estructuralmente, el "estar abajo" en la historia les puede hacer apreciar la vida y la solidaridad de manera muy honda, y les hace más difícil poner su corazón, aunque lo deseasen, en el lujo y en el poder, aunque esto también ocurre en "más pequeño", pues proviene de la condición humana. Y la segunda diferencia es que lo que hay de pecado en el mundo de los pobres, aunque pueda ser también cruel, es "más comprensible", "menos refinado y cínico", no liende a revestirse de "engaño y encubrimiento hipócrita". Recuérdese la delicadeza y la ternura de Jesús hacia el pecador "débil" y su dureza hacia el pecador "poderoso".

Todo esto lo hemos vislo en El Salvador. En tiempos de "normalidad", es decir, de pobreza colidiana, en tiempos, también, de represión y guerra, y más reciente, en tiempos de terremolos, a los pobres les es connatural la decisión primaria de vivir y dar vida, a pesar de dificultades inimaginables para quienes viven en la abundancia o en la suficiencia. Los pobres no sólo son, por humanos, "los guardianes del ser", que decía Heidegger, sino que son, paradójicamente, los "guardianes de la vida", de su sentido, de su insondabilidad. La mujer, sobre todo, es partera de humanidad, y mantiene la maternalidad como referente humano indefectible, sin el cual colapsa la sociedad. Su tragedia puede ser grande, como la que llega de la realidad africana, pero la decisión de mantener la vida en cárceles y refugios supera la imaginación.

33. "Misión actual de la Compañía de Jesús", Revista Latinoamericna de Teología 29 (1993) 120. 
Y esto puede ocurrir por su cercanía a la vida primaria. Indudablemente, la vida básica, primaria, tiene el dinamismo de desplegarse cada vez en más y más vida. En olro contexto escribí "la fenomenología del pan" para mostrar que el pan es siempre "más que pan". La vida es siempre "más que vida". Por su naturaleza, la vida primaria se va desplegando en ámbitos comunitarios, práxicos, éticos, celebrativos, artísticos, religiosos... ${ }^{\mathrm{M}}$. Pero mientras se mantenga la cercanía a lo primario, ese desplegamiento acaece en la dirección correcla, es enriquecedor y humanizante, mientras que si se aleja de lo primario se desvía de lo humano y desemboca en lo innecesario, en lo lujoso, en lo deshumanizante, en el agravio comparativo. Un dinamismo así no convierte al ser humano en "guardián de la vida", pero sí lo hace el dinamismo que se despliega ,desde la primariedad de la vida.

Algo hay en los pobres que quieren vivir, que mantiene la matemalidad con respeclo a la vida, que fascina, subyuga, humaniza y desvela el misterio. Algo hay en ellos que salva e interpela con ultimidad. Por eso, quiero recordar lo que escribi después del terremoto. En el anhelo de vivir y dar vida aparece una como "santidad primordial", que no se pregunla lodavía lo que en ella hay de libertad o de necesidad, de virtud o de obligación, de gracia o de mérilo. Es la santidad que se expresa en una vida colidianamente heroica. Es la santidad del sufrimiento por querer vivir, que tiene una lógica distinta, pero más primaria, que la santidad de la virtud.

En conceptualización teológica, podemos decir que estos pobres, damnificados, víctimas, no son sólo camino a Cristo, sino su sacramento. Son "vicarios de Cristo"3s, como se decía en la edad media, lúcida y nada oscurantista en esto. Tampoco son sólo mediadores que ayudan a salvar la infinita distancia entre los seres humanos y Dios, sino que son, más bien, presencia de Dios. En los conocidos versos de César Vallejo: "El suertero que grita 'La de a mil' contiene no sé qué fondo de Dios"..". Los pobres mantienen con respecto a nosotros esa "alteridad" específica de la divinidad, misteriosa y bienaventurada.

Esta santidad es real, pero repilamos que los pobres cargan también con la pecaminosidad, a veces de forma Irágica. Quisiera decirlo en unas palabras recientes, de Melquisedek Sikuli, obispo de Butembo, República Democrática del Congo, en un congreso por la paz, a finales de febrero de 2001. Enumeró los gravísimos problemas del su país: miseria, injusticia, desplazados, mujeres violadas y aldeas saqueadas, todo ello en el transfondo del colonialismo, que sigue enviando armas para controlar materias primas como el coltán. Pero terminó con

34. Cfr. "La centralidad del reino de Dios", Revisia Latinoamericana de Teología 9 (1986) 274ss.

35. Véase el espléndido libro de J. I. González Faus, Vicarios de Cristo, Mądrid, 1991.

36. Cilado en Gustavo Gutiérrez, El Dios de la vida, Salamanca, 1994, p. 174. 
"el drama de los niños-soldados". No lo escamoteó, citó a Kouroma en su libro Allah no está contento para poner en palabras una tragedia ante la cual sólo parèce posible el silencio: "Cuando no se tiene a nadie en el mundo, ni padre, ni madre, ni hermana, y se es todavía un niño, en un país arruinado y bárbaro, en donde todos se matan, ¿qué se hace? Se empieza a ser niño soldado para comer y matar: es todo lo que nos queda". ${ }^{37}$

Nada de ingenuidad, pues, pero sí honradez con lo real. En medio del mysterium iniquitatis, entre los pobres aparece la santidad primaria -en forma estructural- como en ninguna otra parle. El anhelo primordial de vida, de vivir unos para otros y unos con otros es el primer y lundamental aporte de los pobres a la utopía. Y esa santidad - como el bonum diffusivum sui- se desborda. Una religiosa norleamericana, médico, escribía desde un lugar perdido en El Salvador, en medio de increibles sufrimientos de la gente: "Aquí he encontrado lo que siempre quise que fuese verdad: que el amor es más fuerte que la muerte". Otra religiosa, que ha pasado años en Africa, escribe. "No es difícil alabar y cantar con todo asegurado. La maravilla es que los que resconstruyen sus vidas después de las catástrofes de terremolos, y los presos de Kigali (Rwanda) que recibirán hoy visitas de familiares y que con mil sudores les podrán llevar algo de comer, bendicen y dan gracias a Dios. Hoy he recibido carla de ellos. Tal vez no se dan cuenta cuánlo recibimos de ellos y cómo nos salvan".

\subsection{Convocación e invilación universal}

El mundo ve en los pobres, cuando los mira, lo que en el misterio hay de tremens, lo que causa pavor. Pero en ellos ven también, como en ninguna otra parte, lo que en el misterio hay de fascinans, lo que subyuga y fascina. A eso lo hemos llamado la santidad primaria. $Y$ eso es lo que convoca a los seres humanos e invita a construir la familia humana.

Los pobres tienen la fuerza para retrotraernos a todos a lo real, superando el docetismo, la irrealidad en la que suele vivir el no-pobre; para interpelarnos $a$ todos sobre nuestra propia humanidad, superando el aulo-encubrimiento, la mentira en que suele vivir el no-pobre; para ofrecernos a todos luz y salvación, superando la dormición en que vivimos y la arrogancia y la hybris de quien no necesita nada del débil. Tienen la fuerza para universalizar en verdad la globalización, y, en lenguaje de la tradición, redimirla de su universalismo falaz y deshumanizante. En definitiva, tienen la fuerza para que todos, también los no-pobres, sean beneficiarios, pacientes sociales, no sólo donantes y agentes. Cuando se acepla esto, los seres humanos pueden comprender sus vidas como un llevarse mutuamente unos a otros, dando unos a otros y recibiendo unos de otros. Es la vida en el amor. Es la solidaridad, como máxima expresión de la familia humana, la cual es, a su vez, la máxima expresión de la utopía universal.

37. Véase el texto íntegro de su discurso en Concilium 293 (2001) 818. 
Que los pobres convocan es claro como tesis de fe. En el Antiguo Testamento se dice que el siervo sufriente "ha sido puesto como luz de las naciones" (Is $42,6 ; 49,6)$. $Y$ en el Nuevo Testamento, "Cristo crucificado lo atrae todo hacia si" (Jn 12, 32; 19, 37). Pero también lo es —con un más y un menos, por supuesto- como tesis histórica. Los innumerables movimientos de solidaridad de los últimos años, los pasos más serios en el ecumenismo entre diversas iglesias y religiones, sólo se explican por la atracción que ejercen los pobres, atracción que tiene una doble dimensión de interpelación y de buena noticia, pero baste decir ahora que ahí está.

Hace años, El Salvador no existía para el mundo. Se empezó a conocerlo en 1977, cuando un sacerdole, Rutilio Grande, fue asesinado. El mundo occidental, democrático y cristiano, quedó sorprendido, y algunos quedaron sacudidos. Pero lo más importante es que ese asesinalo llevó al conocimiento de la verdad ignorada: también campesinos, obreros, estudiantes, catequistas y delegados de la palabra, eran masivamente perseguidos, torturados, asesinados. Y se llegó a la verdad fundamental: El Salvador es un pueblo sufriente y crucificado. Esa verdad tuvo fuerza de convocatoria. Los ojos de muchos se posaron en El Salvador, y eso fue un paso importante para la solidaridad. En pequeño, se comenzó a universalizar la utopía y comenzó a surgir la familia humana. Pero, recordémoslo, todo comenzó con las víctimas.

La conclusión es que los pobres convocan y ofrecen y, o facilitan una invitación a vivir con humanidad. Desencadenan un nuevo dinamismo en quien se dirige a ellos: dejarse afectar, ofrecer ayuda, comprometerse. Y todo cambia. La ayuda no es sólo material, sino que es enirega de la persona; y no sólo por un tiempo, sino duraderamente. $Y$ la novedad fundamental es que no se trata ya sólo de dar, sino también de recibir, dar unos a otros y recibir unos de otros lo mejor de cada uno. A eso, usando en sentido amplio una expresión paulina, llamamos entonces el "Ilevarse mutuamente". Había nacido la solidaridad. Es experiencia repetida que muchos venidos de fuera a ayudar en refugios y cantones, confiesan, con agradecimiento, que donde menos lo esperaban, sin merecerlo, por así decirlo, han recibido más de lo que han dado y han recibido algo de un orden superior a lo que ellos traían, en un principio. Han recibido acogida, afecto, esperanza, fe, realidades de las que se hace el tejido humano y con las cuales se puede construir una familia, una comunidad, un pueblo. Se puede universalizar lo humano, pero no uniformándolo, ni dividiéndolo en dos: los de arriba y los de a bajo, los que dan y los que reciben... Lo que ha hecho posible esa nueva forma de estar en la vida ha sido el encuentro con las víctimas, el ayudarlas y el encontrarse, ayudados por ellas.

Y terminemos diciendo que el modelo de solidaridad introduce algo nuevo: la gracia, realidad ausente en la aclual civilización y con gravísimos daños para el ser humano. 
No hemos hablamos del reino de Dios que anunció Jesús, pero ha estado muy presente. No en forma de textos, ni menos de interprelaciones, de lás muchas que hoy existen, sino como una luz que hace ver - así lo esperamos- lo que hoy pueden esperar los pobres de este mundo, cuando se ponen ante su Dios.

El mero hecho de hablar de "utopía", en un mundo que la desconoce, y de hablar "utópicamente" ante una razón en lo fundamental pragmática, es la forma más clara de mantener vivo el hecho fundamental: existe la utopía y existe la esperanza, "crean en la buena noticia, el reino de Dios se acerca". Pero, además, hemos insistido en que los pobres son la reserva y los destinatarios de la utopía, porque "para ellos es el reino de Dios". Y que en los pobres existe el potencial de vivir con espíritu, el que por su naturaleza puede, como la levadura, hacer crecer la masa. "Pobres con espíritu", que decía Ignacio Ellacuría. Y hemos recordado que los pobres son las mayorías, junto a minorías opresoras e insultantes, que hacen de la buena noticia algo contracultural y confictivo. Así pudiéramos seguir.

Quizás dos cosas más haya que añadir. Una es que también hoy la utopía tiene portavoces, entre nosotros, Monseñor Romero, calco historizado en muchas cosas de Jesús de Nazaret, el que amó a los pobres, de verdad y hasta el final. Y la segunda es que, en definitiva, pobres y solidarios despliegan una mesa para lodos, donde no haya primeros ni últimos, "una mesa común con manteles largos para lodos... Cada uno con su taburete y que para todos llegue la mesa, el mantel y el conqué". Estas palabras son de Rutilio Grande, Ires semanas antes de ser asesinado. En El Salvador las entiende todo el mundo. Y creemos que las entienden todos los pobres de este mundo.

Y una última observación. Para formular la utopía, se repite hoy la expresión "un mundo en que quepan todos y nadie quede fuera". Ojala así sea, por supuesto. Pero la formulación no sosiega del todo, pues se "puede caber" de muy diversas maneras. En mi opinión, los pobres "cabrán" cuando estén en el centro. De otra forma, estarán en los márgenes, y de ahí a que queden fuera sólo hay un paso. Esta centralidad de los pobres, que no excluye ni expulsa a nadie, sino que convoca y atrae, puede ser la formulación de la utopía, en nuestro mundo. 